НАУКИ О ЗЕМЛЕ

"НАУКА. ИННОВАЦИИ. ТЕХНОЛОГИИ", №4, 2019

25.00 .35

ГЕОИНФОРМАТИКА

УДК 332.1

Дыба C.E.,

Северо-Кавказский федеральный университет,

Чернова И.В.

г. Ставрополь, Россия

dyba.1997@mail.ru

\title{
РЫНОК ГЕОИНФОРМАЦИОННЫХ ПРОДУКТОВ И УСЛУГ В РОССИИ
}

Введение:

С приходом геоинформационных систем в Россию в начале $90-х$ гг. XX века, стал формироваться динамично развивающийся рынок. Сегодня мы наблюдаем значительные трансформации в информационном секторе в общем и в геоинформационном в частности. Вместе с этим работ, анализирующих изменения структуры и динамики рынка геоинформационных продуктов и услуг в России, востребованности направлений у работодателей, удовлетворенности выпускников полученным образованием и в целом состоянием рынка, который структурирован по трем основным направлениям: навигация, геоинформатика, дистанционное зондирование на сегодняшний день практически нет.

Материалы и методы исследования:

информационной базой исследования послужили объемы затрат на геоинформационные услуги и программное обеспечение в разрезе субъектов России. На основе сайта www.zakupki.gov.ru [2] был произведен подсчет внутрирегиональных расходов на геоинформационные услуги, программное обеспечение и оборудование в 2006-2017 гг.

Результаты исследований

и их обсуждение: составлен реестр наиболее популярных учебных заведений, готовящих специалистов в рассматриваемой области. Выделено 3 типа учебных заведений, в которых ведутся программы подготовки в области картографии, геоинформатики и геодезии с высокими рейтингам, а также дана характеристика равномерности размещения данной образовательной сети по территории России. Кроме того, в статье сопоставляются центры подготовки специалистов, размещение основных компаний, специализирующихся на данном направлении работы и списки вакансий по основным направлениям. Дана оценка профессиональной востребованности выпускников геоинформатиков в условиях современного рынка. Рассмотрены сферы применения профессиональных умений и навыков выпускников, а также описаны основные изменения рынка вакансий на примере Северо-Кавказского федерального университета. Приводятся результаты опроса студентов и выпускников, получивших образование в области геоинформационных технологий. Более подробно рассмотрен процесс трудоустройства выпускников Северо-Кавказского федерального университета в 2008 и 2016 годах на предмет их специализации и приоритета различных сфер применения полученных знаний в области геоинформатики. А также учтено мнение экспертов по ряду профессиональных вопросов.

Выводы. В Везультате исследования удалось определить, что рынок геоинформационных продуктов и услуг сегодня подвергается серьезной трансформации. Геодезическая сфера уступает свои лидирующие позиции современным навигационным технологиям. Большой оборот рынка отмечается в Западной Сибири, Московской и Ленинградской областях, кроме того в Республике Крым. Наряду с этим, такие регионы, как Красноярский край испытывают значительную нехватку специалистов. Основная доля выпускников - геоинформатиков работают по профессии, их ожидания во время обучения зачастую совпадают с реальными условиями работы после вуза.

Ключевые слова: рынок, геоинформационные продукты и услуги, программное обеспечение ГИС, трудоустройство, выпускники, картографы, геоинформатики. 
Dyba S.E.,

Chernoval.V.

Introduction:

Materials and methods of research:

Research results and their discussion:

Conclusions:

Keywords:
North-Caucasus Federal University, Stavropol, Russia

dyba.1997@mail.ru

\section{Geographic Information Products and Services Market in Russia}

with the advent of geographic information systems in Russia in the early 90 -ies of $X X$ century, a dynamically developing market began to form. Today we are witnessing significant transformations in the information sector in General and in the geoinformation sector in particular. At the same time, there are practically no works analyzing the changes in the structure and dynamics of the market of geoinformation products and services in Russia, the demand for directions among employers, the satisfaction of graduates with their education and the overall state of the market, which is structured in three main directions: navigation, Geoinformatics, remote sensing.

the information base of the study was the volume of costs for geoinformation services and software in the context of the subjects of Russia. Site-based www.zakupki.gov.ru [2] intraregional expenditures for geographic information services, software and equipment in $2006-2017$ were calculated.

the register of the most popular educational institutions training specialists in the field under consideration is compiled. There are 3 types of institutions, which are training programmes in the field of cartography, Geoinformatics and geodesy with high ratings, as well as the characteristic uniformity of this educational network in Russia. In addition, the article compares training centers, placement of the main companies specializing in this area of work and lists of vacancies in the main areas. The estimation of professional demand of graduates of Geoinformatics in the conditions of the modern market is given. Spheres of application of professional skills of graduates are considered, and also the main changes of the market of vacancies on the example of the North Caucasian Federal University are described. The results of the survey of students and graduates educated in the field of geoinformation technologies are presented. The process of employment of graduates of the North Caucasus Federal University in 2008 and 2016 for their specialization and priority of different areas of application of the knowledge in the field of Geoinformatics is considered in more detail. The opinion of experts on a number of professional issues was also taken into account.

as a result of the study, it was possible to determine that the market of geoinformation products and services is undergoing a major transformation today. Geodetic sphere gives its leading position to modern navigation technologies. A large turnover of the market is observed in Western Siberia, Moscow and Leningrad regions, in addition to the Republic of Crimea. Along with this, regions such as the Krasnoyarsk territory are experiencing a significant shortage of specialists. The main share of graduatesGeoinformatics work by profession, their expectations during training often coincide with the real conditions of work after the University.

market, geoinformation products and services, GIS software, employment, graduates, cartographers, geoinformatics.

\section{Введение}

В настояшее время геоинформационные технологии прочно вошли и обосновались в жизни современного общества. Сферы применения ГИС разнообразны: сельское хозяйство, промышленность, экономика и даже культура. Такая популярность обусловлена возможностями оперативно получать информацию по запросу и визуализировать ее, выявлять скрытые 
взаимосвязи и тенденщии, которые трудно или невозможно заметить, используя привычные бумажные карты.

За короткую историю появления и развития ГИС на рынке геоинформационных продуктов и услуг наблюдался как рост оборота рынка, так и его спад, менялась структура рынка. Причины колебаний имеют различный характер, среди них кризис экономики, введение санкций, развитие технологий и др. Отследить и спрогнозировать каким образом реагировал рынок на современные внешние факторы и изменения сложная и очень актуальная задача. В целом, анализ рынка - это комплексное и всестороннее изучение той области рынка, где реализовывается товар или услуга, подлежащая изучению. Для производителя комплексный, а главное - качественный анализ рынка даст возможность не только увидеть реальную ситуацию, но и поможет применить необходимые маркетинговые инструменты для продвижения товара или услуги на рынке, а значит, даст возможность увеличить прибыль и занять лидируюшее место на рынке.

Активное развитие геоинформационных систем в России приходится на начало девяностых годов. Если в то время еще стоял вопрос выживания отечественных разработчиков программных продуктов (ПП) в условиях жесткой конкуренции с импортными продуктами, то сегодня мы скорее задумаемся о возможности замещения иностранных ПП российскими. Данная проблема возникла еще в начале 2000 -х годов. Введенные экономические санкции против России обострили данную проблему импортозамещения программного обеспечения обработки пространственных данных. Так, на Экономическом форуме в г. Санкт-Петербурге в 2014 году В.В. Путин установил дальнейший путь развития экономики России в сторону импортозамещения. Определив, при этом основное направление - это промышленность [7].

\section{Материалы и методы исследования}

В ходе исследования мы выделили 3 направления рынка геоинформационных систем - это данные дистанционного зондирования, навигация и геодезия. Проанализировали все 3 сектора на основе сайта www. zakupki.gov.ru [2]. Так, были подсчитаны затраты на программное обеспечение и оборудование в регионах. В рамках исследования был произведен опрос экспертов, которые прокомментировали ситуацию с динамикой рынка геоинформационных продуктов и услуг, дали пояснения по поводу отказа от иностранного программного обеспечения, а также прокомментировали снижающуюся популярность термина «геоинформационные технологии» в отечественном медиапространстве.

Интересным сюжетом стал обзор вузов, которые готовят специалистов в области картографии, геоинформатики и геодезии. Нами был проведен мониторинг специализированных вузов, выделили 3 типа учебных заведений с высокими рейтингам, которые выпускают специалистов разного профиля. Кроме 
того, сопоставили центры подготовки специалистов и востребованность выпускников в тех или иных регионах России. Для этих целей проанализировали все вакансии в области геоинформатики и смежньх отраслей на одном из наиболее популярных ресурсов по подбору кадров HeadHunter [6].

Данное исследование предполагает учет мнения специалистов, окончивших учебные заведения или проходящими подготовку по анализируемому нами профилю. Таким образом, нами было проведено анкетирование в google форме студентов и выпускников, получивших образование в области геоинформационных технологий. В данном опросе приняли участие 193 человека в возрасте от 18 до 48 лет. Результаты данного опроса представили в виде графиков и диаграмм.

\section{Результаты исследования и их обсуждение}

В 2017 году основные расходы на геодезические услуги отмечаются в таких регионах как Центральная Сибирь и Дальний Восток. Лидирующими по этому показателю стали Красноярский край, Иркутская область, Республика Саха (рис. 1). Основные затраты в этих субъектах были связаны с такими виды работ, как: создание геодезической разбивочной основы для капитального ремонта автомобильных дорог А-331, Р-255, а также инженерно-геодезическими изысканиями, для строительства физкультурно-оздоровительного комплекса с ледовой ареной в Иркутской области, г. УсольеСибирское и др. Отметим, что по данному виду затрат не отстает и республика Башкоркостан, где средства выделялись на создание геодезической разбивочной основы по объектам: «Капитальный ремонт моста через реку Сорочка на км $238+459$ автомобильной дороги М-5», а также на ремонт автомобильных дорог. Кроме того, лидерами являются Московская и Ленинградская области. Стоит отметить и Республику Крым, расходы которой сопоставимы с лидерами, так как ведется активное освоение территории полуострова. Менее развиты геодезические услуги в ряде регионов Центральной России, республиках Северного Кавказа, а также на Востоке России - это Забайкальский край и Чукотская область.

Анализируя затраты на геоинформационные услуги (рис. 2), можно сказать, что абсолютным лидером по закупкам является Новосибирская область, потратившая более 60 млн руб. Основные затраты пришлись на оказание услуги по модернизации региональной геоинформационной системы Новосибирской области. Также надо отметить Центр Сибири, а именно: Красноярский край, Ханты-Мансийский автономный округ и Свердловскую область, где затраты составляют более 10 млн руб. Менее развиты геоинформационные услуги в Северо-Западном и Дальневосточном Федеральном округах. Важно отметить также Республику Крым, где большая часть затрат с суммой более 20 млн руб. пришлась на создание региональной геоинформационной системы Республики Крым (2-й этап). 


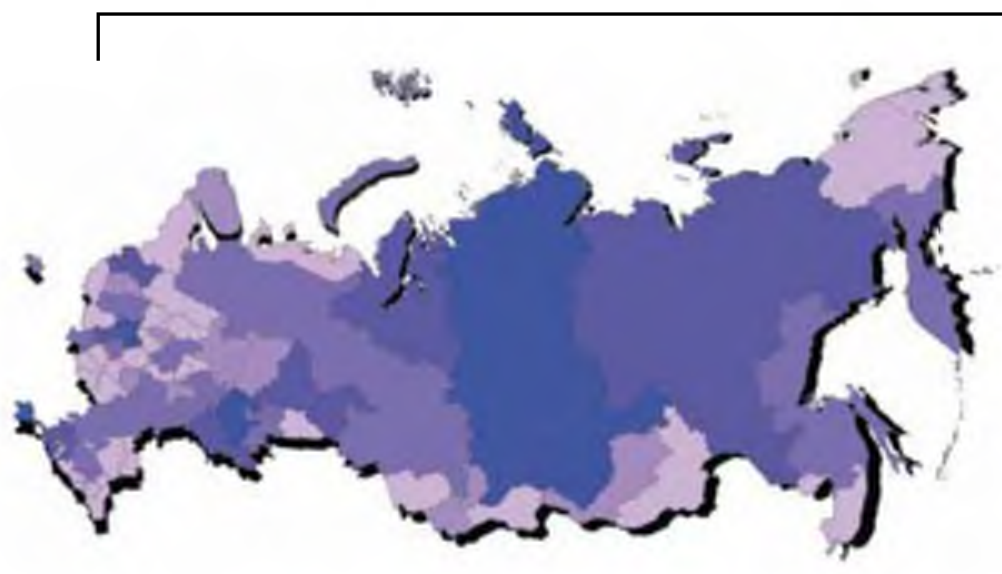

Затраты на геодезические услуги (руб.)

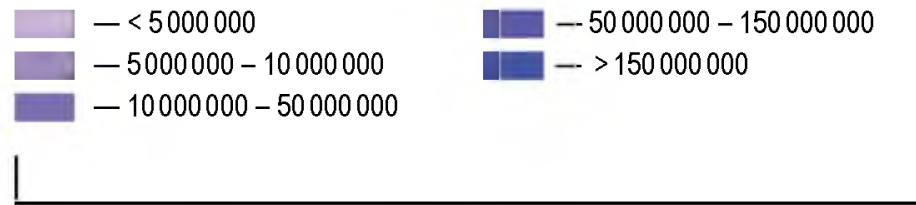

Рис. 1.

\section{Затраты на геодезические услуги В субъектах РФ на 2017 год.}

Fig. 1. Costs for geodetic services in the constituent entities of the Russian Federation for 2017.

Главными драйверами роста являются развитие технологий умных городов и урбанизация, интеграция геоинформационных технологий с бизнесаналитикой и растущее внедрение ГИС в транспортную отрасль.

Основные затраты на навигационные услуги (рис. 3.) отмечались в Уральском, Северо-Восточном и Центральном федеральных округах, а также Краснодарском крае с затратами на навигационные услуги свыше 40 млн руб выигрышно выделяется по данному критерию. Основные расходы в этих регионах были на такие виды работ, как: поставка спутникового геодезического навигационного оборудования ГЛОНАCC/GPS, предоставление аэронавигационной информации, поставка навигационных терминалов и др. Также, стоит отметить регион средней Сибири и Республику Саха (Якутия), где затраты составляют свыше 10 млн руб. Менее развиты навигационные услуги в таких регионах, как: Республика Чита, Тыва, Алтай, Ненецкий автономный округ, Пензенская, Тамбовская, Липецкая, Тверская и другие области. 


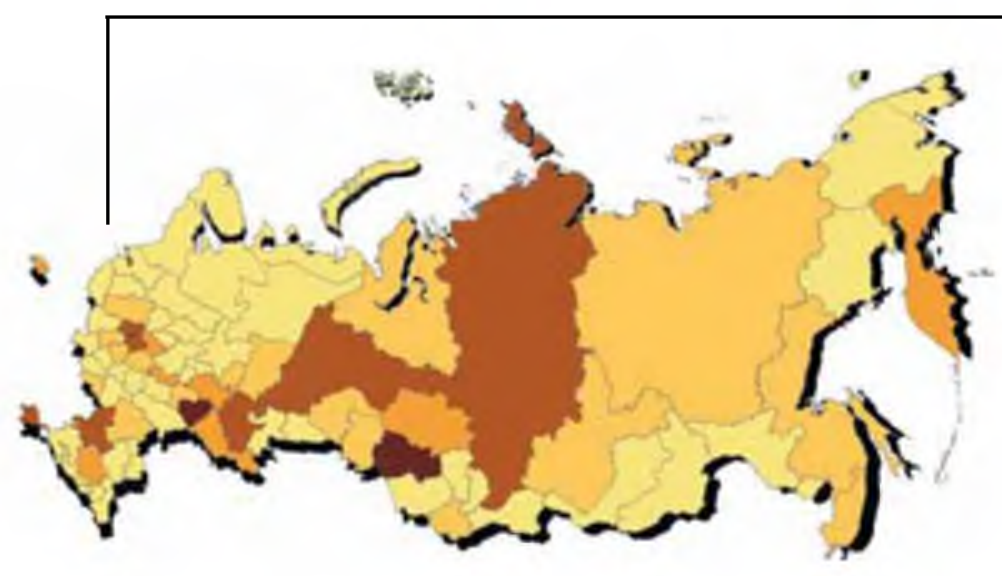

Затраты на геоинформационные услуги (руб.)

$-<1000000$

$-1000000-5000000$

$-10000000-50000000$

$-5000000-10000000$

$\rightarrow>50000000$

Pис. 2.

Затраты на геоинформационные услуги в субъектах РФ на 2017 год.

Fig. 2. Costs for geoinformation services in the constituent entities of the Russian Federation for 2017.

В результате анализа затрат на программное обеспечение и оборудование в 2017 г. отмечаем, что больше всего закупок проходило в сфере геодезии (свыше 500 млн руб) это объясняется тем, что геодезические приборы наиболее дорогостоящие, в то время как в сфере геоинформатики (100 млн руб.) и навигации (160 млн руб) существенная доля идет скорее на оплату труда специалистов.

Стоит отметить, что наблюдаются тенденции к росту навигационного рынка, что связано с возрастающей популярностью навигационных устройств, включению чипов GPS (ГЛОНАСС) в большее количество мобильных устройств. Теперь это не только дорогие смартфоны и автонавигаторы, но и обычные телефоны и планшеты. В тоже время геоинформатика также, как и геодезия уступает свои позиции в пользу навигации.

По прежнему популярным является иностранное оборудование и программное обеспечение, так по оценкам опрощенных экспертов процесс отказа от иностранного программного обеспечения, обозначенный в 2014 г., проходит 


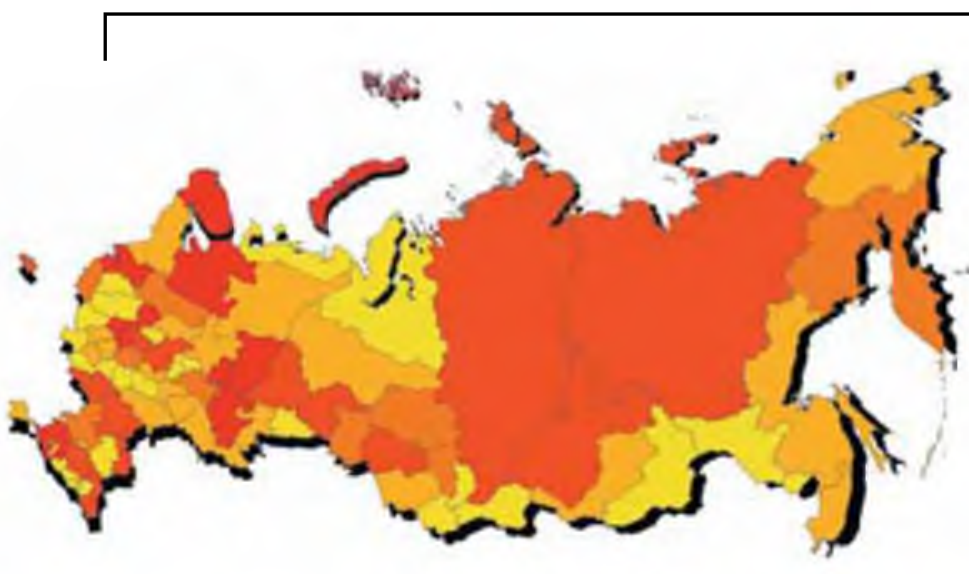

Затраты на навигационные услуги (руб.)

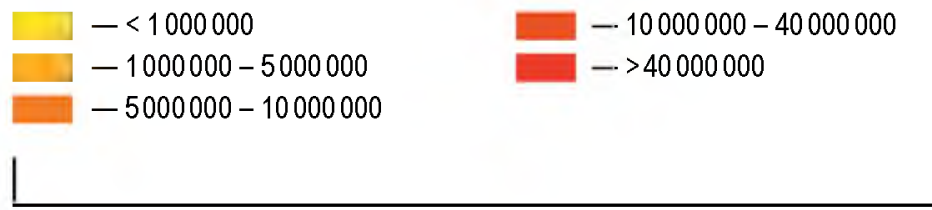

Рис. 3.

Затраты на навигационные услуги в субъектах РФ на 2017 год.

Fig. 3. Costs for navigation services in the constituent entities of the Russian Federation for 2017.

вялотекущими темпами, а большие компании и вовсе ведут две системы (российское и зарубежное ПО). Ожидается, что в период с 2017 по 2023 г. на рынке ГИС-оборудования будут доминировать мобильные устройства сбора геоданных (Gis collectors). Кроме того, эксперты предполагают, что пик популярности термина «геоинформационные технологии» приходился на 2014-2015 гг. и был связан с активностью использования приложений для смартфонов с геолокационной платформой. Отмечают, что затем данный термин заменили такие термины как «интернет вещей», «smart city» и «блокчейн».

Удалось выделить 3 типа учебных заведений с высокими рейтингам, которые выпускают специалистов разного профиля. Среди основных вузов Московский Государственный университет геодезии и картографии (МИИГАиК), Пермский Государственный национальный исследовательский университет (ПГНИУ), Сибирский Государственный университет геосистем и технологий (СГУГиТ). Профессиональные учебные заведения распределены по территории России неравномерно. Основная их концентрация приходится 
на европейскую часть. То же самое относится и к распределению крупных компаний, работающих в сфере геоинформационных услуг.

Мы проанализировали вакансии специалистов в области геодезии и картографии на сайте www.hh.ru [6] Наибольшее число вакансий обнаружены в Уральском и Сибирском федеральньх округах. А именно в Красноярском, Алтайском краях, а также Иркутской, Новосибирской, Омской и Тюменской областях. Открытых вакансий геодезистов на время запроса было более 13 . Также по числу открытых вакансий наравне с этими регионами находится Краснодарский край. Специалисты этой области мало востребованы в Центральном и Дальневосточном федеральных округах.

Что касается картографов, то в таких регионах как Республики Бурятия и Хакасия, Кемеровская и Читинская области поиск работы будет затруднен. Лидером является Красноярский край с 13 открытыми вакансиями. Мало или нет совсем вакансий в ряде регионов на Дальневосточном и Центральном федеральных округах (рис. 4).

Нами было проведено анкетирование студентов и выпускников, получивших образование в области геоинформационных технологий. Всего в анкетировании приняло участие 193 человека в возрасте от 18 до 48 лет. Гендерный состав респондентов распределился поровну. В опросе поучаствовали $39 \%$ студентов и $61 \%$ выпускников таких вузов как СКФУ, ВолГУ, КубГУ, МИИГАиК, СПбГУ, МГУ и др. вузов страны. Кроме этого, на вопросы анкеты ответили 3 выпускника направления подготовки землеустройство и кадастр, 7 выпускников - географов, 5 выпускников с квалификацией эколог и природопользователь.

По результатам анкетирования удалось выяснить, что 51\% всех опрошенных респондентов связали свою профессиональную деятельность с геоинформатикой. В информационном направлении смежных сфер деятельности, таких как маркетинг, сельское хозяйство, информационно-аналитический центр, туризм, экономика, консалтинговые услуги и индивидуальное предпринимательство работает $21 \%$ опрошенных. Менее трети опрошенных, а именно $28 \%$ не нашли себя в области ГИС и связали свою профессиональную деятельность с торговлей, бизнесом и творчеством.

Причину смены профессиональных интересов респонденты видят в том, что работа по специальности низкооплачиваемая, сложность при устройстве на работу ввиду отсутствия опыта, а также некоторым выпускникам требовался более высокий уровень высшего образования (специалист, магистр). Интересно то, что студент данных направлений считают основными проблемами при трудоустройстве отсутствие опыта (51\%), а также незнание рынка труда и неумение презентовать себя ( 18 и $21 \%$ соответственно).

Среди опрошенных $60 \%$ выпускников занимают должности специалистов, $25 \%$ являются руководителями отделов, либо организаций. Остальные 15\% - это преподаватели, ассистенты, дизайнеры, инженеры и др. 
Картографы, ГИС-специалисты

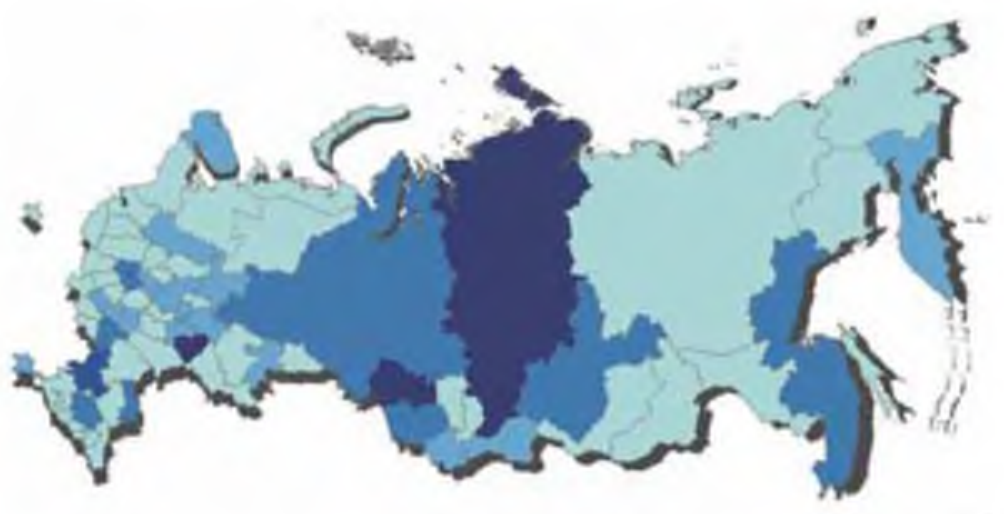

\section{Геодезисты}

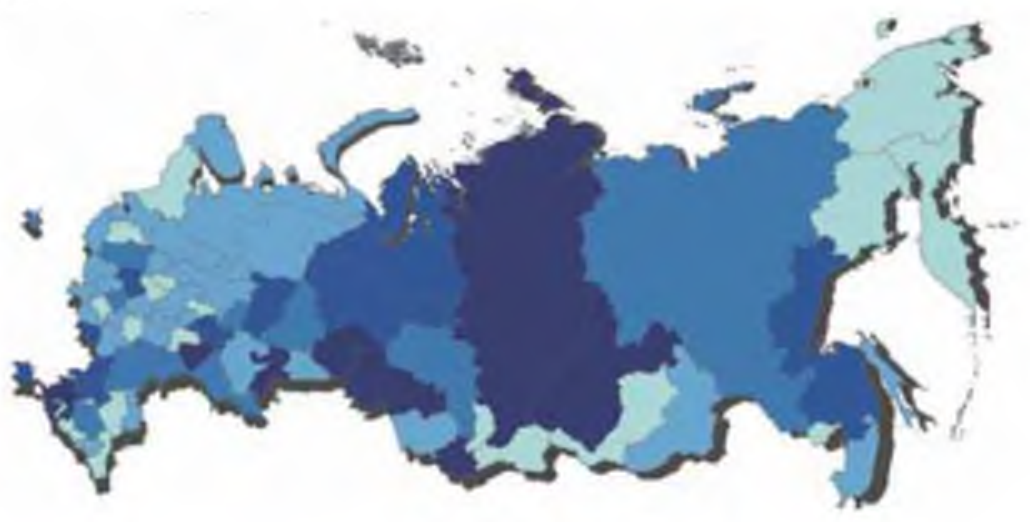

УСЛОВНЫЕ ОБОЗНАЧЕНИЯ

Вакансии специалистов

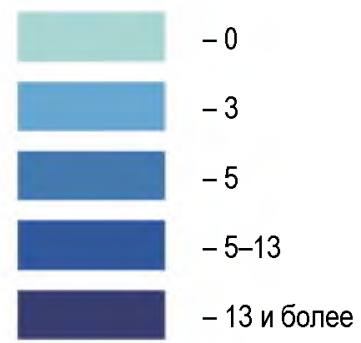

Рис. 4.

Вакансии специалистов на сайте HeadHunter.

Fig. 4. Specialist vacancies on the site HeadHunter. 
Что касается уровня доходов, то реальная заработная плата выпускников, работающих по специальности, соответствует желаемой заработной плате студентов. А именно 55\% выпускников имеют доходы более 30 тыс. рублей в месяц. Кроме того, $79 \%$ респондентов ответили, что работают в своем регионе и им не требовался переезд на другое место жительства в связи с работой.

Выпускники-геоинформатики считают, что имеют отличные перспективы в будущем и их работа успешна, именно так ответило $38 \%$ опрошенных.

Отметим, что несмотря на введенные экономические санкции против России и последующий отказ от использования иностранного программного обеспечения $80 \%$ интервьюированных выпускников, работающих в различных сферах деятельности, по прежнему пользуются зарубежным программным обеспечением, таким как ArcGis, Qgis, Mapinfo Professional, AutoCad. Из российского программного обеспечения лидирующим является ГИС Панорама.

Что касается трудоустройства выпускников Северо-Кавказского федерального университета, то сегодня оно кардинально поменялось. Если в 2008 году 40\% выпускников трудоустраивалась в сферу геодезии, то в 2016 году в эту сферу трудоустроились лишь 7\%. Также, на $17 \%$ сократилось и трудоустройство в бюро технической инвентаризации (БТИ). На 10\% выросла доля принятых на работу в организации, занимающиеся исключительно геоинформационными технологиями. С развитием ГИС и их широкими функциональными возможностями значительно выросла сфера архитектурного проектирования, если в 2008 г. от всей доли трудоустройства это было всего $2 \%$, то в 2016 г. это составило $23 \%$. Выпускники стали трудоустраиваться на предприятия, работающие в сфере территориального проектирования. В 2016 году это составило $5 \%$ от всей доли выпускников.

\section{Выводы}

Доля затрат на геоинформационные услуги меняется в пользу навигации, что обусловлено пиком ее активного развития и внедрения. Спрос на геодезические услуги и вакансии падает, но продолжает оставаться достаточно высоким. Основными потребителями геоинформационных продуктов и услуг являются Западная Сибирь, Санкт-Петербург и Московская область. 


\section{Библиографический список}

1. Ахмеров Т. М. Кому нужна собственная Гис [Электронный ресурс]: Режим доступа: http://www.comnews.ru/node/77986 (Дата обращения: 05.02.2018).

2. Единая информационная система в сфере закупок [Электронный ресурс]: Режим доступа: http://zakupki.gov.ru/epz/main/ public/home.html свободный (Дата обращения: 09.04.2018).

3. Новости IT бизнеса [электронный ресурс]: Режим доступа: https://www.it-weekly. ru/it-news/analytics/119063. html свободный (Дата обращения: 11.04.2018).

4. Рынок геоинформатики России в 2006 г. Состояние, проблемы и перспективы развития [электронный ресурс]: Режим доступа: http://www. gisa.ru/38507.html. свободный (Дата обращения: 11.04.2018).

5. Сайт бухгалтерской отчетности предпринимателей [электронный ресурс]: Режим доступа: http://www.rusprofile.ru/свободный (Дата обращения: 09.04.2018).

6. Сайт поиска вакансий HeadHunter [электронный ресурс]: Режим доступа: https://hh.ru/свободный (Дата обращения: 09.04.2018).

7. Яроцкая Е.В., Патов А.М. Развитие отечественных географических информационных систем в условиях импортозамещения // Полиметалический сетевой электронный научный журнал Кубанского государственного аграрного университета. 2016. №117. C. $175-188$.

\section{References}

1. Ahmerov T. M. Komu nuzhna sobstvennaya Gis [Elektronny] resurs]: Rezhim dostupa: http://www.comnews.ru/node/77986 (Data obrashcheniya: 05.02.2018).

2. Edinaya informacionnaya sistema $\vee$ sfere zakupok [Elektronnyj resurs]: Rezhim dostupa: http://zakupki.gov.ru/epz/main/public/ home.html svobodnyj (Data obrashcheniya: 09.04.2018).

3. Novosti IT biznesa [elektronnyj resurs]: Rezhim dostupa: https:// www.it-weekly.ru/it-news/analytics/119063.html svobodnyj (Data obrashcheniya: 11.04.2018).

4. Rynok geoinformatiki Rossii $\vee 2006$ g. Sostoyanie, problemy i perspektivy razvitiya [elektronnyj resurs]: Rezhim dostupa: http://www. gisa.ru/38507.html. svobodnyj (Data obrashcheniya: 11.04.2018).

5. Sajt buhgalterskoj otchetnosti predprinimatelej [elektronnyj resurs]: Rezhim dostupa: http://www.rusprofile.ru/svobodnyj (Data obrashcheniya: 09.04.2018).

6. Sajt poiska vakansij HeadHunter [elektronnyj resurs]: Rezhim dostupa: https://hh.ru/svobodnyj (Data obrashcheniya: 09.04.2018).

7. YArockaya E.V., Patov A.M. Razvitie otochestvennyh geograficheskih informacionnyh sistem $v$ usloviyah importozameshcheniya // Polimetalicheskij setevoj elektronnyj nauchnyj zhurnal Kubanskogo gosudarstvennogo agrarnogo universiteta. 2016. № 117. S. $175-188$. 
Поступило в редакцию 19.11.2019, принята к публикации 02.12.2019

\section{6 aвторах}

Дыба Сергей Евгеньевич, магистр направления Картография и геоинформатика Института математики и естественных наук Северо-Кавказского федерального университета, Scopus ID: - Researcher ID: -, телефон: (918)808-39-47 E-mail: dyba.1997@mail.ru.

Чернова Ирина Владимировна, к.г.н., доцент кафедры социальноэкономической географии, геоинформатики и туризма института математики и естественных наук Северо-Кавказского федерального университета, Scopus ID: -, Researcher ID: -, телефон: (918)885-79-37 E-mail: chernova_skfu@mail.ru.

\section{About the authors}

Dyba Sergej Evgen'evich, master of the direction of Cartography and Geoinformatics of the Institute of mathematics and natural Sciences North-Caucasus Federal University, Scopus ID: - Researcher ID: -, phone: (918)808-39-47 E-mail: dyba.1997@mail.ru .

Chernova Irina Vladimirovna, $\mathrm{PhD}$, assistant Professor of social and economic geography, Geoinformatics and tourism of the Institute of mathematics and natural Sciences North-Caucasus Federal University, Scopus ID: -, Researcher ID: -, phone: (918)885-79-37. E-mail: chernova_skfu@mail.ru. 